\title{
Issues in Infants with Prader-Will Syndrome: Special Review on Early Dietary Intervention and Early Use of Growth Hormone
}

\author{
Sung Yoon Cho, M.D. \\ and Dong-Kyu Jin, M.D.
}

Department of Pediatric, Samsung Medical Center, Sungkyunkwan University School of Medicine, Seoul, Republic of Korea
Received: 8 September, 2012

Accepted: 10 September, 2012

Address for correspondence: Dong-Kyu Jin, M.D.

Department of Pediatrics, Samsung Medical Center, Sungkyunkwan University School of Medicine, 81 Irwon-ro, Gangnam-gu, Seoul 135-710, Korea

Tel: +82.2-3410-3525

Fax: $+82.2-3410-0043$

E-mail: jindk@skku.edu
Prader-Willi syndrome (PWS) is a complex multisystem genetic disorder characterized by hypothalamic-pituitary dysfunction. The main clinical features consist of neonatal hypotonia, distinctive facial features, delayed overall development with mental deficiency, behavioral abnormalities, poor growth in infancy followed by overeating with severe obesity, short stature, and hypogonadism. Recently, patients with PWS have been diagnosed at an earlier age, especially in the neonatal period. In addition, early interventions such as commencement of growth hormone therapy and dietary programs, have received attention in PWS treatment. Since early diagnosis is now possible based on both clinical symptoms and signs and on molecular genetic criteria, early dietary intervention and early growth hormone therapy during the first two years may improve neurodevelopment, increase muscle mass, and reduce obesity. Our aim in this review is to document the characteristics of infants with PWS and to provide a recent update regarding early management.

Key Words: Prader-Willi syndrome; Growth hormone; Obesity; Hyperphagia; Infant

\section{Introduction}

Prader-Willi syndrome (PWS) is a complex multisystem genetic disorder characterized by hypothalamic-pituitary dysfunction ${ }^{1,2}$. The main clinical features consist of neonatal hypotonia, distinctive facial features, delayed overall development with mental deficiency, behavioral abnormalities, poor growth in infancy followed by overeating with severe obesity, short stature, and hypogonadism ${ }^{3)}$. Many features of PWS indicate a deficiency in growth hormone (GH) production, including low growth velocity despite obesity, reduced lean body mass, low insulin-like growth factor-I (IGF-I) levels, and low insulin levels ${ }^{4,5}$. These findings provide a rationale for GH therapy in PWS. Weight development in PWS is unique: at birth, body weight is slightly reduced, while during the first two years of life, body weight is low or normal due to poor feeding. This period is followed by rapid weight gain, resulting in a weightfor-height index exceeding the normal range at the age of ten years in nearly all patients with $\mathrm{PWS}^{6}$. Recently, patients with PWS have been diagnosed at earlier ages, especially during the neonatal period. In addition, early interventions, including commencement of GH therapy and dietary programs, have received attention in PWS therapy. Our aim in this review is to document the characteristics of infants with PWS and to provide a recent update on early management.

\section{Genetics and Diagnosis in PWS}

The various genomic changes causing PWS lead to the loss of expression of the paternally 
expressed genes on chromosome 15q11.2-q13 through loss or failure of expression; this is because silencing of the maternal contribution has been programmed by epigenetic factors (e.g., DNA methylation) $)^{7}$. Three mechanisms have been described: paternal deletion, maternal disomy (mUPD), and deficient imprinting ${ }^{3)}$. Parent-of-origin-specific DNA methylation can be used to confirm the clinical diagnosis of PWS patients in all 3 molecular classes. The most widely used DNA methylation test targets the 5' end of the SNRPN locus ${ }^{8,9)}$. Normal individuals have both a methylated and an unmethylated allele, whereas individuals with PWS have only the maternally methylated allele.

\section{Characteristics of PWS in the newborn and infant period}

Severe hypotonia is consistently observed at birth and during the neonatal period ${ }^{10)}$. Neonatologists appear to be on the frontline of early diagnosis, including PWS in the differential diagnosis of severe neonatal hypotonia ${ }^{11)}$. The patients with PWS have recently been diagnosed at earlier ages, especially in the neonatal period. The first stage of PWS, occurring in infancy, is characterized by lethargy, marked hypotonia, global developmental delay, and small genitalia with frequent cryptorchidism $^{12)}$. Patients with PWS have characteristic dysmorphic features including a narrow bifrontal diameter, almond-shaped palpebral fissures, narrow nasal bridge, and thin upper lip with a down-turned mouth. These patients very commonly have shorter total hand size, narrow palms with hypoplastic hypothenar bulges, and short feet with short toes. On physical examination, the neonates with PWS can show the 'head lagging sign' and 'frog leg position. Fair hair and hypopigmentation of the eyes and skin relative to other family members are frequently observed in patients with deletion-type PWS; these features are less commonly observed in patients with uniparental disomy. Gross motor and language milestones are delayed. Early milestones are reached on average at double the normal age (e.g., sitting at 12 months, walking at 24 months, and words at 2 years).

\section{Growth hormone deficiency in PWS}

More than $85 \%$ of patients with PWS are GH deficient ${ }^{5)}$. Although length at birth is normal, growth velocity is significantly decreased after 2-3 years and the mean final adult height is $2 \mathrm{SD}$ scores below normal ${ }^{13)}$.

\section{Effects of growth hormone therapy}

GH treatment at the currently recommended dosage for children with PWS $(0.03 \mathrm{mg} / \mathrm{kg} /$ day $)$ restored linear growth and final adult height without inducing serious adverse effects ${ }^{14-16)}$.
Low lean body mass (LBM) in PWS most likely reflects a reduced muscle mass and may therefore contribute to clinical hypotonia, poor physical performance, and as a result, reduced energy expenditure ${ }^{5)}$. A randomized controlled GH trial in patients with PWS showed that LBM, corrected for height and sex, did not increase during GH-treatment, but LBM did significantly decrease in the control group, which suggests that $\mathrm{GH}$ prevents reduction in $\mathrm{LBM}^{14)}$. Some studies report major increases in bone mass density with GH treatment ${ }^{17)}$.

\section{GH therapy in infants with PWS}

Although GH therapy in PWS has various beneficial effects, the body composition and physical function (muscle strength and agility) remain abnormal even after 4 years of GH therapy ${ }^{18)}$. These persistent manifestations of the syndrome might reflect non-GH-related abnormalities intrinsic to PWS and/or the late initiation of GH therapy following a critical period of adipose and muscle development during infancy ${ }^{12)}$. Therefore, it is important to evaluate the effects of early GH therapy on the physical findings and neurodevelopment of infants and toddlers with PWS. In one study that included similar-aged children with PWS who had received or not received long-term GH therapy, the strongest evidence to date showed that GH therapy, when started early in life, beneficially and significantly altered the natural history of PWS by reducing body fat and improving muscle strength, physical function, and lipid profiles without adverse effects ${ }^{19)}$. Thus, physicians and families can favorably weigh the sustained long-term value of GH treatment in infantile patients with PWS. The Samsung Medical Center treats nearly 220 patients with PWS, and about 110 of these patients were diagnosed during infancy. Although children younger than 2 years of age are not covered by health insurance in Korea, GH therapy has been started in infants in recent years after obtaining informed consent from their parents. Their growth curves and development relative to chronologic age have improved with $\mathrm{GH}$ therapy. There have been no severe side effects. However, a long-term follow-up of these patients treated with GH may be needed. We recommend that GH treatment should be started at 4-6 month of age at a low dose, such as $0.25-0.30 \mathrm{mg} / \mathrm{m}^{2} /$ day or $0.009-0.012 \mathrm{mg} / \mathrm{kg} /$ day and increased during the first weeks and months to reach the standard replacement $\mathrm{GH}$ dose of approximately $1.0 \mathrm{mg} / \mathrm{m} 2 /$ day or $0.035 \mathrm{mg} / \mathrm{kg} /$ day. Clinical effects, such as sleep apnea and increases in the level of IGF-I, should be monitored, particularly if there is a clinical suspicion of overtreatment (edema, worsening or new development of snoring, headache, and/or acromegalic clinical features) ${ }^{20)}$.

\section{Mechanism of the effects of GH therapy in infants with PWS}

Administration of GH to infants and toddlers with PWS in a randomized, controlled trial resulted in normalized height, 
increased accrual of lean body mass, and reduction in percent body fat after 1 year of treatment. The 2 -year data showed that the accumulation of excess body fat was delayed and reduced but not prevented; these results were similar to those of an earlier study that reported a body fat SDS of +3 after 2.5 years of $\mathrm{GH}$ treatment ${ }^{21)}$. The age at independent walking was younger than typical for the syndrome, at $23.3 \pm 4.8$ months in this study and at 24.1 months in a previous study ${ }^{22)}$. Subjectively, the GHtreated infants and toddlers were reported to be more alert and energetic by their families. An increased rate of language and cognitive development was noted in the treated group. It is unclear whether these results arise solely from the known effects of GH therapy on muscle tone. However, the concomitant increase in head growth suggests that a central nervous system effect may also play a role ${ }^{12)}$.

In one study, IGF-I levels increased rapidly during GH treatment from below the normal range to the high-normal range $^{23)}$. IGF-I receptors have been localized in several areas of the human brain, indicating that IGF-I may have a neuroregulatory role in the central nervous system ${ }^{24)}$. Theoretically, IGF-I may directly influence the central nervous system or GH might induce local IGF-I expression in brain tissue, thereby improving psychomotor development ${ }^{23)}$. Another possible explanation for the improvement in mental development during GH treatment might be that the improved motor development allows children to sit, stand, and walk independently. This could enable them to explore and interact more with their environment, thereby improving their mental development ${ }^{23)}$. Another study showed that a significant improvement in both mental and motor development in PWS infants and toddlers after 1 year of GH treatment when compared to randomized controls (Fig. 1) ${ }^{23)}$. Head circumference increased from low-normal to normal during $\mathrm{GH}$ treatment. Greater improvements were seen in children with an initially lower motor developmental age than with a higher initial motor developmental age, indicating that early treatment with GH might be beneficial.

\section{Concerns in $\mathrm{GH}$ therapy}

\section{1) Obstructive sleep apnea}

Patients with PWS are at risk of obstructive sleep apnea (OSA) for several reasons, including obesity ${ }^{25)}$, facial dysmorphism (including micrognathia and a small naso- or oropharynx) ${ }^{26)}$, sticky secretions $^{27)}$, and hypotonia ${ }^{28)}$. One hypothesis for the association between GH therapy and deaths during upper respiratory infections is that GH treatment may cause enlargement of the tonsils and adenoids, which would narrow
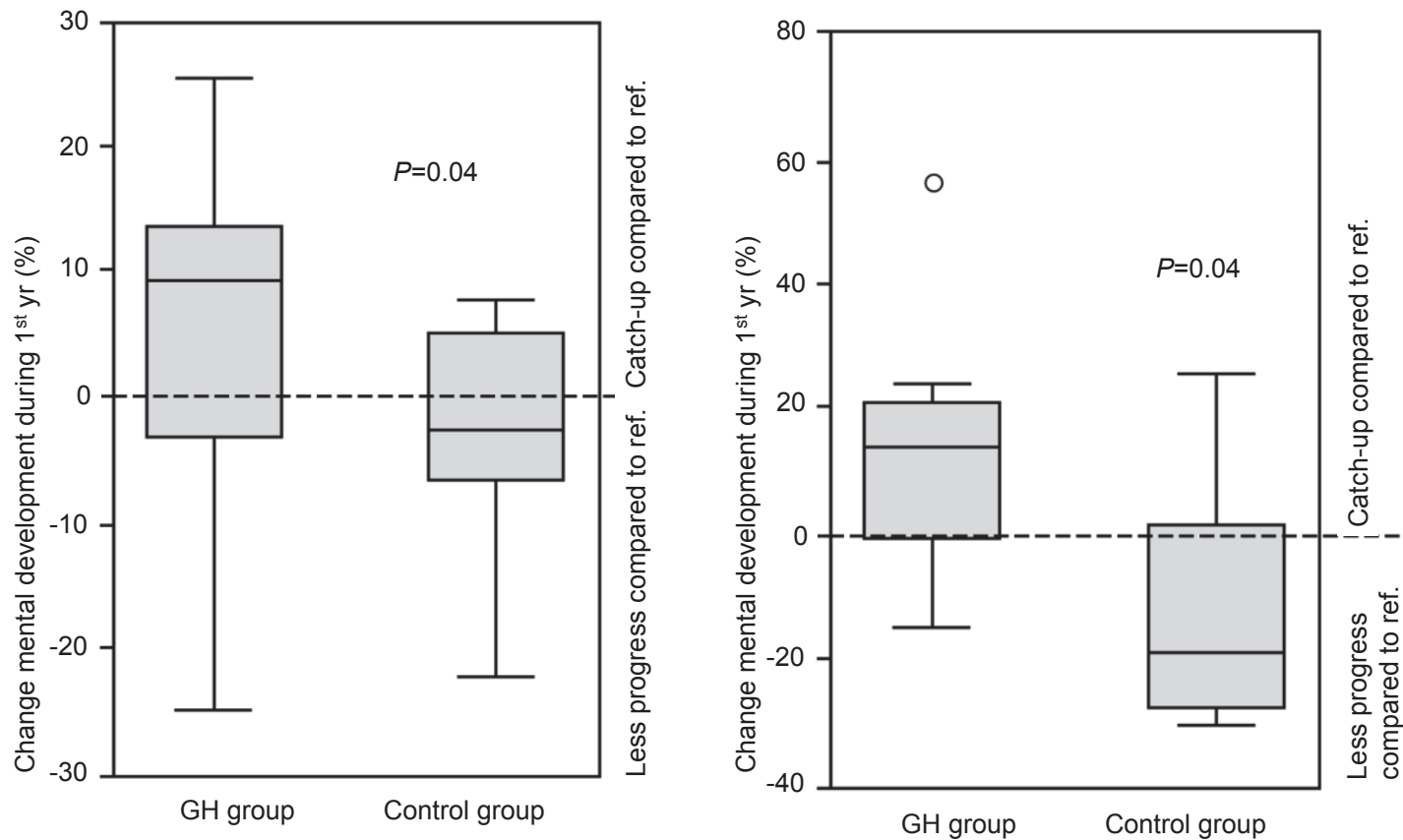

Fig. 1. Changes in mental (A) and motor (B) development during 12 months of study. Psychomotor development was assessed at baseline and after 12 months with BSID-II. BSID-II yields two scores: mental developmental age (in months) and motor developmental age (in months). The mental scale consists of items in relation to visual and auditory information processing, language development, memory, eye-hand coordination, imitation, and problem solving. The motor scale assesses gross and fine motor skills. The lower boundary of the boxplot is the 25th percentile and the higher boundary is the 75th percentile. The line in the box represents the median. Lines are drawn from the smallest to the largest observed value that is not an outlier. The horizontal line represents no change compared to normal children (change of 0\%). A positive value represents a catch-up, compared to normal children, whereas a negative value represents less progress compared to normal children. (Adapted from Festen et

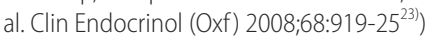


the already small airways of children with PWS ${ }^{29)}$. Another hypothesis proposes fluid retention early in therapy as the mechanism underlying the development of symptoms of $\mathrm{OSA}^{30}$. A causal relationship between GH and sudden death has not been demonstrated, although important concerns over safety have been raised. A pragmatic approach, where the balance of benefit vs. risk favors treatment with GH, is to closely monitor each individual for symptoms of OSA and to repeat polysomnograms as clinically indicated ${ }^{31}$.

\section{2) Carbohydrate metabolism}

Children with PWS show fasting insulin levels that are lower than those in body mass index (BMI)-matched children with simple obesity ${ }^{32}$. These low insulin levels suggest an increased insulin sensitivity, probably related to GH deficiency ${ }^{5}$. Insulin resistance in children with PWS may be associated with BMI, even in the absence of $\mathrm{GH}$ treatment ${ }^{33)}$. In a prospective cohort study $^{33)}$, despite a favorable effect of GH on body composition and lipid profile in PWS children, their insulin levels increased during therapy. Therefore, carbohydrate metabolism (glucose, hemoglobin A1c) should be closely monitored in patients receiving $\mathrm{GH}$.

\section{3) Scoliosis}

The rapid growth associated with GH may aggravate this spinal deformity. Some authors have described an association between increased GH levels and a higher rate of curve progression in children without $\mathrm{PWS}^{34-36)}$. In contrast to these reports, one randomized controlled trial in a large group of children with PWS showed no significant difference between GH-treated children and randomized controls with regard to onset of scoliosis, curve progression, and start of treatment of scoliosis ${ }^{37)}$. Frequent physical examinations and yearly radiographic examination are therefore recommended, independently from GH treatment.

\section{Hyperphagia and Obesity}

\section{Nutritional phase in PWS}

PWS has been classically described as having two nutritional stages: failure to thrive in infancy, followed by hyperphagia in later childhood. One study ${ }^{38)}$ described a total of seven nutritional phases of PWS (Table 1). In general, infants with PWS cannot suckle properly and many are gavage-fed ${ }^{39}$. They often fail to thrive, although Eiholzer et al. ${ }^{21)}$ reported that even underweight infants with PWS have abnormally high body-fat measures. An interesting facet of PWS is hyperphagia, which is almost universal after the age of 3 years ${ }^{39}$. Treatment with GH has been shown to improve linear growth and to decrease fatmass to muscle-mass ratios ${ }^{21}$, but it appears to have little, if any, effect on the abnormal eating behaviors of people with PWS. Little research has been carried out regarding the transition period between the early childhood phenotype of failure to thrive and the older, hyperphagic phenotype. One study, by Butler et al. ${ }^{40)}$, sheds light on this under-investigated stage of the disorder. Overall, these researchers found considerable variation in the age at which children first exhibited an increased interest in food, and significantly fewer children displayed the full food obsession pattern of behavior than would be expected from other reports. However, the standard deviation scores for BMI tended to increase around 30 months of age, before any notable increase in the characteristic eating behavior as reported by many parents, thereby supporting the suggestion that, in fact, three stages are involved in the development of PWS: failure to thrive in infancy, increased BMI or obesity in early childhood, and hyperphagia leading to greater obesity in later childhood and adulthood ${ }^{40)}$. A larger-scale longitudinal study could usefully explore the use of GH in infancy and clarify the apparent delay in the transition between phenotypic stages resulting from the treatment.

\section{Mechanism of hyperphagia}

Overeating in PWS can be elucidated by the following theoretical models: a problem of satiety as opposed to hunger; the role of inner physiological awareness and its potential effects on feelings of hunger and satiation; hyperresponsive reward systems and food as a substance of abuse; the direct consequence of genetics on the hypothalamic feeding pathway; and the role of the prenatal environment ${ }^{41)}$. In one study, the analysis of 18F-FDG PET images of PWS children revealed metabolic abnormalities in brain regions that are directly or indirectly related with food intake and obsessive-compulsive behavior ${ }^{42)}$.

In recent years, there has been a drive to understand hormonal mechanisms that control appetite and eating in PWS. Ghrelin, which stimulates hunger, is synthesized principally in the stomach. In the gastric body and fundus, 2- to 3 -fold increases in the numbers of ghrelin-expressing cells and in the amounts of ghrelin were noted in PWS patients vs. comparison groups ${ }^{43}$. However, gastric emptying in PWS was reduced, despite higher ghrelin levels, and the voracious appetite associated with PWS appeared to be related to another mechanism ${ }^{44}$. Ghrelin may be involved in the instigation of the binging and hyperphagic

Table 1. Clinical characteristics of the nutritional phases

\begin{tabular}{ll}
\hline Phase & Clinical characteristics \\
\hline Phase 0 & $\begin{array}{l}\text { Decreased fetal movements and lower birth weight } \\
\text { Phase 1a }\end{array}$ \\
Pypotonia with difficulty feeding (0-9 mo)
\end{tabular}


stage $^{41)}$.

\section{Early weight control}

The weight of PWS patients starts to increase between 18 and 36 months of age, without a significant increase in food intake (Fig. 2$)^{40)}$. That is, the obesity begins before a substantial increase in food intake or interest. Therefore, early management of eating behavior is important. At present, the only available control for hyperphagia for most people with PWS is close mentoring by caregivers and life-long restricted access to food, with food cupboards and refrigerators often being locked. In one study about early dietary intervention in PWS children, early dietary intervention, starting in the second year of life and continued until the age of 10 years, was effective in avoiding excessive weight gain in patients with PWS ${ }^{45}$. A macronutrient diet with $25 \%$ protein, $20 \%$ fat (reduction of $33-50 \%$ of the recommended daily fat intake), and 55\% modified carbohydrate (a significant reduction in mono- and disaccharides) was decisive in controlling hyperphagia and food craving behavior in children with PWS. However, those diets had a negative effect on growth ${ }^{45}$. Therefore, GH may be an important additional treatment in these patients.

\section{Other considerations}

\section{Hypothyroidism}

Thyroid axis dysfunction seems to be a frequent feature in infants with PWS. Pediatricians should be aware of this association, in order to evaluate this possibility in PWS during this critical period of thyroid hormone action on neurological development. This is especially important since neonatal TSH screening is not an accurate tool for diagnosing thyroid axis dysfunction ${ }^{46}$. Published data on thyroid hormone levels in PWS children treated with GH therapy are very limited. Free T4, T3, and TSH levels should be monitored regularly in PWS children, particularly during $\mathrm{GH}$ treatment ${ }^{477}$.

\section{Cryptorchidism}

The majority of individuals with PWS have a dysfunctional hypothalamic-pituitary-gonadal axis, which manifests as retarded or incomplete sexual development. Neonatal hypogonadism is difficult to assess in girls, but boys affected by PWS often have small penises and/or undescended testicles, both of which are indications of prenatal hypogonadotropic hypogonadism $^{48)}$. Most clinicians agree that cryptorchidism should be corrected to enable detection of testicular malignancies.

\section{Adrenal insufficiency}

Several reports have indicated a mortality rate for PWS patients estimated at $3 \%$ yearly ${ }^{49-52)}$. Disturbances in the hypothalamus-hypophysis-adrenal axis have been hypothesized to be responsible for these events or, at least, to represent concurrent factors consistent with an inadequate or late response during infections or relevant dehydration episodes ${ }^{53)}$. Central adrenal insufficiency (CAI) is likely to result from an inappropriate corticotrophin releasing hormone secretion

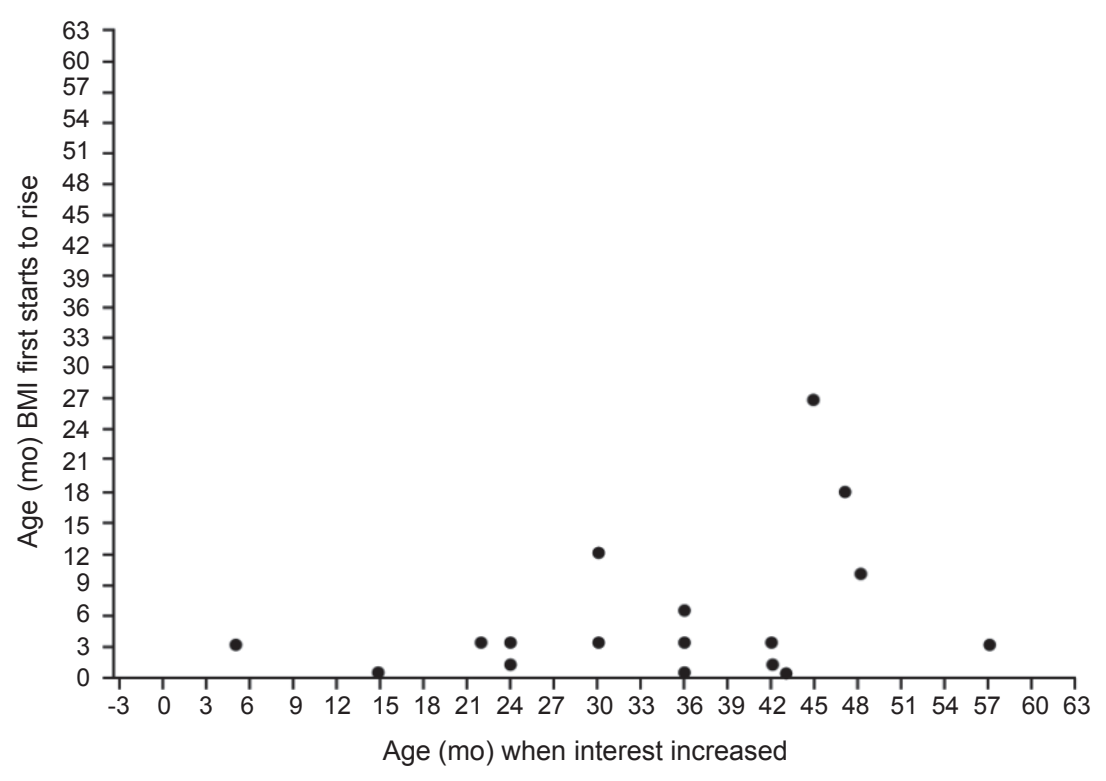

Fig. 2. Age when body mass index (BMI) first rises consecutively for 6 months relative to interest in food increasing beyond normal. Increased interest in food was usually reported as having started later than any

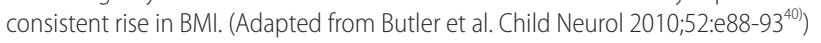


by the hypothalamus. In particular, del15 patients, females, obese, and older patients are reported at a higher risk of $\mathrm{CAI}^{53}$. Although clinically relevant adrenal failure in PWS children is rare, glucocorticoid treatment during intercurrent illness should be considered in PWS patients without a recently proven normal adrenal function. A replacement treatment with hydrocortisone at $30-70 \mathrm{mg} / \mathrm{m}^{2} /$ day, divided into 3 doses, should be warranted in cases of moderate/severe stress in all PWS infants ${ }^{53)}$.

\section{Dental problems}

Stephenson ${ }^{54)}$ reported sticky saliva to be a diagnostic indicator of PWS in neonates, and thick, viscous saliva has been a consistent finding in PWS ${ }^{5,56)}$. Oral findings, including caries $^{57-60)}$, enamel defects ${ }^{60-63)}$ and poor oral hygiene ${ }^{59,60)}$, are described. Owing to low salivary flow rate and higher risk of gingival inflammation, prevention with regular professional cleaning as part of a comprehensive oral preventive program is particularly important for individuals with PWS.

Monitoring of reduced salivation and increased caries by 1 year of age should be considered.

\section{Conclusion}

Since early diagnosis is now possible, based on both clinical symptoms and signs and on molecular genetic criteria, early dietary intervention and early GH therapy during the first two years may improve neurodevelopment, increase muscle mass, and reduce obesity in PWS infants. This review endeavored to summarize characteristics of PWS in the newborn and infant periods and to provide useful information for optimizing their management. However, long-term safety studies are required, particularly regarding the effects of GH treatment on glucose metabolism and scoliosis. The parents of today's infants and children with PWS have better access to information and support than was available to past generations. As we become more aware of the health effects and long-term prospects for people with this disorder, the practical advice and guidelines available to family caregivers will increase further.

\section{References}

1) Smith A, Egan J, Ridley G, Haan E, Montgomery P, Williams $\mathrm{K}$, et al. Birth prevalence of Prader-Willi syndrome in Australia. Arch Dis Child 2003;88:263-4.

2) Vogels A, Van Den Ende J, Keymolen K, Mortier G, Devriendt K, Legius E, et al. Minimum prevalence, birth incidence and cause of death for Prader-Willi syndrome in Flanders. Eur J Hum Genet 2004;12:238-40.

3) Cassidy SB, Dykens E, Williams CA. Prader-Willi and Angelman syndromes: sister imprinted disorders. Am J
Med Genet 2000;97:136-46.

4) Eiholzer U, Bachmann S, l'Allemand D. Is there growth hormone deficiency in prader-willi Syndrome? Six arguments to support the presence of hypothalamic growth hormone deficiency in Prader-Willi syndrome. Horm Res 2000;53 Suppl 3:44-52.

5) Burman P, Ritzen EM, Lindgren AC. Endocrine dysfunction in Prader-Willi syndrome: a review with special reference to GH. Endocr Rev 2001;22:787-99.

6) Wollmann HA, Schultz U, Grauer ML, Ranke MB. Reference values for height and weight in PraderWilli syndrome based on 315 patients. Eur J Pediatr 1998;157:634-42.

7) Glenn CC, Driscoll DJ, Yang TP, Nicholls RD. Genomic imprinting: potential function and mechanisms revealed by the Prader-Willi and Angelman syndromes. Mol Hum Reprod 1997;3:321-32.

8) Glenn CC, Saitoh S, Jong MT, Filbrandt MM, Surti U, Driscoll DJ, et al. Gene structure, DNA methylation, and imprinted expression of the human SNRPN gene. Am J Hum Genet 1996;58:335-46.

9) Kubota T, Das S, Christian SL, Baylin SB, Herman JG, Ledbetter DH. Methylation-specific PCR simplifies imprinting analysis. Nat Genet 1997;16:16-7.

10) Trifiro G, Livieri C, Bosio L, Gargantini L, Corrias A, Pozzan G, et al. Neonatal hypotonia: don't forget the Prader-Willi syndrome. Acta Paediatr 2003;92:1085-9.

11) Bachere N, Diene G, Delagnes V, Molinas C, Moulin P, Tauber M. Early diagnosis and multidisciplinary care reduce the hospitalization time and duration of tube feeding and prevent early obesity in PWS infants. Horm Res 2008;69:45-52.

12) Myers SE, Whitman BY, Carrel AL, Moerchen V, Bekx MT, Allen DB. Two years of growth hormone therapy in young children with Prader-Willi syndrome: physical and neurodevelopmental benefits. Am J Med Genet A 2007;143:443-8.

13) Butler MG, Meaney FJ. Standards for selected anthropometric measurements in Prader-Willi syndrome. Pediatrics 1991;88:853-60.

14) Festen DA, de Lind van Wijngaarden R, van Eekelen M, Otten BJ, Wit JM, Duivenvoorden HJ, et al. Randomized controlled GH trial: effects on anthropometry, body composition and body proportions in a large group of children with Prader-Willi syndrome. Clin Endocrinol (Oxf) 2008;69:443-51.

15) Lin HY, Lin SP, Tsai LP, Chao MC, Chen MR, Chuang $\mathrm{CK}$, et al. Effects of growth hormone treatment on height, weight, and obesity in Taiwanese patients with Prader-Willi syndrome. J Chin Med Assoc 2008;71:305-9.

16) Angulo MA, Castro-Magana M, Lamerson M, Arguello R, Accacha S, Khan A. Final adult height in children with Prader-Willi syndrome with and without human growth hormone treatment. Am J Med Genet A 2007;143A:1456- 
61.

17) Myers SE, Carrel AL, Whitman BY, Allen DB. Sustained benefit after 2 years of growth hormone on body composition, fat utilization, physical strength and agility, and growth in Prader-Willi syndrome. J Pediatr 2000;137:42-9.

18) Carrel AL, Myers SE, Whitman BY, Allen DB. Benefits of long-term GH therapy in Prader-Willi syndrome: a 4-year study. J Clin Endocrinol Metab 2002;87:1581-5.

19) Carrel AL, Myers SE, Whitman BY, Eickhoff J, Allen DB. Long-term growth hormone therapy changes the natural history of body composition and motor function in children with prader-willi syndrome. J Clin Endocrinol Metab 2010;95:1131-6.

20) Marik PE, Pastores SM, Annane D, Meduri GU, Sprung CL, Arlt W, et al. Recommendations for the diagnosis and management of corticosteroid insufficiency in critically ill adult patients: consensus statements from an international task force by the American College of Critical Care Medicine. Crit Care Med 2008;36:1937-49.

21) Eiholzer U, L'Allemand D, Schlumpf M, Rousson V, Gasser T, Fusch C. Growth hormone and body composition in children younger than 2 years with Prader-Willi syndrome. J Pediatr 2004;144:753-8.

22) Eiholzer U, Malich S, I'Allemand D. Does growth hormone therapy improve motor development in infants with Prader-Willi syndrome? Eur J Pediatr 2000;159:299.

23) Festen DA, Wevers M, Lindgren AC, Bohm B, Otten BJ, Wit JM, et al. Mental and motor development before and during growth hormone treatment in infants and toddlers with Prader-Willi syndrome. Clin Endocrinol (Oxf) 2008;68:919-25.

24) Adem A, Jossan SS, d'Argy R, Gillberg PG, Nordberg A, Winblad B, et al. Insulin-like growth factor 1 (IGF-1) receptors in the human brain: quantitative autoradiographic localization. Brain Res 1989;503:299-303.

25) Redline S, Tishler PV, Schluchter M, Aylor J, Clark K, Graham G. Risk factors for sleep-disordered breathing in children. Associations with obesity, race, and respiratory problems. Am J Respir Crit Care Med 1999;159:1527-32.

26) Richards A, Quaghebeur G, Clift S, Holland A, Dahlitz M, Parkes D. The upper airway and sleep apnoea in the PraderWilli syndrome. Clin Otolaryngol Allied Sci 1994;19:193-7.

27) Schluter B, Buschatz D, Trowitzsch E, Aksu F, Andler W. Respiratory control in children with Prader-Willi syndrome. Eur J Pediatr 1997;156:65-8.

28) Holm VA, Cassidy SB, Butler MG, Hanchett JM, Greenswag LR, Whitman BY, et al. Prader-Willi syndrome: consensus diagnostic criteria. Pediatrics 1993;91:398-402.

29) Eiholzer U. Deaths in children with Prader-Willi syndrome. A contribution to the debate about the safety of growth hormone treatment in children with PWS. Horm Res 2005;63:33-9.

30) Fillion M, Deal C, Van Vliet G. Retrospective study of the potential benefits and adverse events during growth hormone treatment in children with Prader-Willi syndrome. J Pediatr 2009; 154:230-3.

31) Nixon GM, Rodda CP, Davey MJ. Longitudinal association between growth hormone therapy and obstructive sleep apnea in a child with Prader-Willi syndrome. J Clin Endocrinol Metab 2011;96:29-33.

32) Eiholzer U, l'Allemand D. Growth hormone normalises height, prediction of final height and hand length in children with Prader-Willi syndrome after 4 years of therapy. Horm Res 2000;53:185-92.

33) Colmenares A, Pinto G, Taupin P, Giuseppe A, Odent T, Trivin C, et al. Effects on growth and metabolism of growth hormone treatment for 3 years in 36 children with PraderWilli syndrome. Horm Res Paediatr 2011;75:123-30.

34) Ahl T, Albertsson-Wikland K, Kalen R. Twenty-four-hour growth hormone profiles in pubertal girls with idiopathic scoliosis. Spine (Phila Pa 1976) 1988;13:139-42.

35) Skogland LB, Miller JA. Growth related hormones in idiopathic scoliosis. An endocrine basis for accelerated growth. Acta Orthop Scand 1980;51:779-80.

36) Willner S, Nilsson KO, Kastrup K, Bergstrand CG. Growth hormone and somatomedin A in girls with adolescent idiopathic scoliosis. Acta Paediatr Scand 1976;65:547-52.

37) de Lind van Wijngaarden RF, de Klerk LW, Festen DA, Duivenvoorden HJ, Otten BJ, Hokken-Koelega AC. Randomized controlled trial to investigate the effects of growth hormone treatment on scoliosis in children with Prader-Willi syndrome. J Clin Endocrinol Metab 2009;94:1274-80.

38) Miller JL, Lynn CH, Driscoll DC, Goldstone AP, Gold JA, Kimonis V, et al. Nutritional phases in Prader-Willi syndrome. Am J Med Genet A 2011;155A:1040-9.

39) Cassidy SB, Driscoll DJ. Prader-Willi syndrome. Eur J Hum Genet 2009;17:3-13.

40) Butler JV, Whittington JE, Holland AJ, McAllister CJ, Goldstone AP. The transition between the phenotypes of Prader-Willi syndrome during infancy and early childhood. Dev Med Child Neurol 2010;52:e88-93.

41) McAllister CJ, Whittington JE, Holland AJ. Development of the eating behaviour in Prader-Willi Syndrome: advances in our understanding. Int J Obes (Lond) 2011;35:188-97.

42) Brandau DT, Lund M, Cooley LD, Sanger WG, Butler MG. Autistic and dysmorphic features associated with a submicroscopic 2q33.3-q34 interstitial deletion detected by array comparative genomic hybridization. Am J Med Genet A 2008;146A:521-4.

43) Sahoo T, Bacino CA, German JR, Shaw CA, Bird LM, Kimonis V, et al. Identification of novel deletions of 15q11q13 in Angelman syndrome by array-CGH: molecular characterization and genotype-phenotype correlations. Eur J Hum Genet 2007; 15:943-9.

44) Santamaria R, Blanco M, Chabas A, Grinberg D, Vilageliu L. Identification of 14 novel GLB1 mutations, including 
five deletions, in 19 patients with GM1 gangliosidosis from South America. Clin Genet 2007;71:273-9.

45) Schmidt H, Pozza SB, Bonfig W, Schwarz HP, Dokoupil K. Successful early dietary intervention avoids obesity in patients with Prader-Willi syndrome: a ten-year follow-up. J Pediatr Endocrinol Metab 2008;21:651-5.

46) Vaiani E, Herzovich V, Chaler E, Chertkoff L, Rivarola MA, Torrado M, et al. Thyroid axis dysfunction in patients with Prader-Willi syndrome during the first 2 years of life. Clin Endocrinol (Oxf) 2010;73:546-50.

47) Festen DA, Visser TJ, Otten BJ, Wit JM, Duivenvoorden HJ, Hokken-Koelega AC. Thyroid hormone levels in children with Prader-Willi syndrome before and during growth hormone treatment. Clin Endocrinol (Oxf) 2007;67:44956.

48) Bray GA, Dahms WT, Swerdloff RS, Fiser RH, Atkinson RL, Carrel RE. The Prader-Willi syndrome: a study of 40 patients and a review of the literature. Medicine (Baltimore) 1983;62:59-80.

49) Nagai T, Obata K, Tonoki H, Temma S, Murakami N, Katada Y, et al. Cause of sudden, unexpected death of Prader-Willi syndrome patients with or without growth hormone treatment. Am J Med Genet A 2005;136:45-8.

50) Grugni G, Crino A, Bosio L, Corrias A, Cuttini M, De Toni T, et al. The Italian National Survey for Prader-Willi syndrome: an epidemiologic study. Am J Med Genet A 2008;146:861-72.

51) Einfeld SL, Kavanagh SJ, Smith A, Evans EJ, Tonge BJ, Taffe J. Mortality in Prader-Willi syndrome. Am J Ment Retard 2006;111:193-8.

52) Tauber M, Diene G, Molinas C, Hebert M. Review of 64 cases of death in children with Prader-Willi syndrome (PWS). Am J Med Genet A 2008;146:881-7.

53) Corrias A, Grugni G, Crino A, Di Candia S, Chiabotto
P, Cogliardi A, et al. Assessment of central adrenal insufficiency in children and adolescents with Prader-Willi syndrome. Clin Endocrinol (Oxf) 2012;76:843-50..

54) Stephenson JB. Neonatal presentation of Prader-Willi syndrome. Am J Dis Child 1992;146:151-2.

55) Hart PS. Salivary abnormalities in Prader-Willi syndrome. Ann N Y Acad Sci 1998;842:125-31.

56) Bailleul-Forestier I, Verhaeghe V, Fryns JP, Vinckier F, Declerck D, Vogels A. The oro-dental phenotype in PraderWilli syndrome: a survey of 15 patients. Int J Paediatr Dent 2008;18:40-7.

57) Bazopoulou-Kyrkanidou E, Papagiannoulis L. Prader-Willi syndrome: report of a case with special emphasis on oral problems. J Clin Pediatr Dent 1992;17:37-40.

58) Salako NO, Ghafouri HM. Oral findings in a child with Prader-Labhart-Willi syndrome. Quintessence Int 1995;26:339-41.

59) Bots CP, Schueler YT, Brand HS, van Nieuw Amerongen A. [A patient with Prader-Willi syndrome. Characteristics, oral consequences and treatment options]. Ned Tijdschr Tandheelkd 2004;111:55-8.

60) Scardina GA, Fuca G, Messina P. Oral diseases in a patient affected with Prader-Willi syndrome. Eur J Paediatr Dent 2007;8:96-9.

61) Anavi Y, Mintz SM. Prader-Labhart-Willi syndrome. Ann Dent 1990;49:26-9.

62) Bassarelli V, Baccetti T, Bassarelli T, Franchi L. [The dentomaxillofacial characteristics of the Prader-LabhartWilli syndrome. A clinical case report]. Minerva Stomatol 1991;40:811-9.

63) Banks PA, Bradley JC, Smith A. Prader-Willi syndrome-a case report of the multidisciplinary management of the orofacial problems. Br J Orthod 1996;23:299-304. 